Check for updates

The BMJ

Cite this as: BMJ 2021;372:n702 http://dx.doi.org/10.1136/bmj.n702 Published: 12 March 2021

\section{Covid-19: NHS will keep offering vaccinations to those who refuse, says minister}

Gareth lacobucci

The NHS will continue to contact and hold one-to-one meetings with doctors and other staff who haven't taken up the offer of a covid-19 vaccine to tackle any hesitancy, the vaccines minister said this week.

Nadhim Zahawi told the Women and Equalities House of Commons Committee on 10 March that, although uptake among health staff had been "incredibly high"-with over 90\% of those offered so far taking up the vaccine-the NHS was not resting on its laurels. "If you are looking after a vulnerable person, then it is your professional duty if offered the jab to take the jab," he said.

Zahawi acknowledged that uptake had been lower among some groups of the general public, such as black and ethnic minority communities, which he said the government was tackling through a range of measures including a media campaign in many different languages, new community champions, and outreach with healthcare providers and faith leaders.

He added that some hesitancy had also been driven by the spread of misinformation that covid-19 vaccines could affect the fertility of women and men, which is "proving to be quite sadly quite potent," despite clinical experts saying there is no evidence for the claims. ${ }^{1}$

"We've got the NHS talking to their staff who haven't [taken up the offer] on a one-to-one basis," he said. "Some of the evidence suggests that those 10-15 minute conversations make a huge difference to staff."

Zahawi said that, as the national vaccination programme moves through the different priority groups, people who might have been hesitant to be vaccinated initially would be approached again and invited to take up the offer of vaccination. "We keep the offer [of vaccination] evergreen," he said.

"We've already got GPs talking to some of the patients who were eligible who've had a number of contacts [to offer them a vaccine] and haven't taken them up. With the over 70s, we've already begun the recontact to say, 'If you've missed your chance for whatever reason, if you wanted to wait a little bit longer, please come forward again and have your vaccination.' We'll constantly return to make sure we are nudging up those numbers to as high as possible. If we can get to where the [Office for National Statistics] suggests, which is $94 \%$ of the adult population vaccinated, that's a great place to be."

But Zahawi said that the high uptake overall was evidence that the UK's vaccine messaging strategy had been successful. "We are absolutely not complacent or resting on our laurels," he said. "But in terms of uptake, this is the highest uptake, I think, in the history of vaccine deployment in the UK. We already have very high levels of vaccine positivity, I think very much because the strategy has been right. And we've seen sadly in some other countries, for whatever reason, they have tripped over and reinforced some of the negative messaging around vaccines that cost lives at the end of the day."

1 lacobucci G. Covid-19: No evidence that vaccines can affect fertility, says new guidance. BMJ 2021;372:n509. doi: 10.1136/bmj.n509 pmid: 33608302

This article is made freely available for use in accordance with BMJ's website terms and conditions for the duration of the covid-19 pandemic or until otherwise determined by BMJ. You may use, download and print the article for any lawful, non-commercial purpose (including text and data mining) provided that all copyright notices and trade marks are retained. 